\title{
Topic Study Group No. 13: Teaching and Learning of Geometry-Secondary Level
}

\author{
Ui Hock Cheah, Patricio G. Herbst, Matthias Ludwig, \\ Philippe R. Richard and Sara Scaglia
}

\section{The Programme}

The TSG13 program was organized to focus on the following themes:

- Curricular issues in school geometry

- Technological tools and environments for the study of geometry

- Applications of geometry for modeling real world situations and the study of other disciplines

- Connections between geometry and the study of other branches of mathematics

- Connections between geometry and mathematical practices and processes such as argumentation and proof, visualization, figuration, and instrumentation

- Student conceptions and learning of geometrical ideas and their use in geometric problem solving

- Youth and adult geometrical competencies out of school and at the workplace

- Practices and problems in the teaching of geometry

- Geometry, teacher preparation, and teacher knowledge.

Alain Kuzniak from Université Paris Diderot was the invited speaker for TSG13. His keynote touched on the need of theoretical benchmarks in Geometry Education

Co-chairs: Ui Hock Cheah, Patricio G. Herbst.

Team members: Matthias Ludwig, Philippe R. Richard, Sara Scaglia.

\author{
U.H. Cheah \\ Institute of Teacher Education, Cyberjaya, Malaysia \\ e-mail: uhcrecsam1@gmail.com \\ P.G. Herbst $(\bowtie)$ \\ University of Michigan, Ann Arbor, USA \\ e-mail: pgherbst@umich.edu \\ (C) The Author(s) 2017 \\ G. Kaiser (ed.), Proceedings of the 13th International Congress on Mathematical \\ Education, ICME-13 Monographs, DOI 10.1007/978-3-319-62597-3_40
}


research. A total of 16 papers from were reviewed and selected to be presented at the TSG13 sessions.

Invited and selected papers

\section{Tuesday 26 July 2016}

Research on geometry education: the need of theoretical benchmarks (Kuzniak, Alain)

The articulation of geometry problems: a major educational challenge (Richard, Philippe R.)

\section{Wednesday 27 July 2016}

How to develop spatial ability? results from the research project Geodikon (Maresch, Günter)

Students' use of property knowledge and spatial visualization in reasoning about 2D rotations (Frazee, Leah Michelle; Battista, Michael; Joswick, Candace; Clayton; Emanuel)

Epistemological features of a constructional approach to regular 4-polytopes (Berendonk, Stephan; Sauerwein, Marc)

Symbiosis between specialised and pedagogical knowledge in geometry (Chinnappan, Mohan; White, Bruce; Trenholm, Sven)

Geometry teachers' knowledge: insights from the trapezoid study (Manizade, Agida; Martinovic, Dragana)

Playnig with geometry: a game, an educational inquiry activity or an assessment TASK? (Soldano, Carlotta; Luz, Yael)

\section{Friday 29 July 2016}

Exploring models of secondary geometry achievement (Senk, Sharon Louise; Thompson, Denisse Rubilee)

Typical errors in geometry of grade 9 learners in south africa (Steyn, Carine; Morar, Tulsi)

The growth of mathematical understanding: elif's engagement with representations in pirie-kieren levels (Gulkilik, Hilal; Ugurlu, Hasan Hüseyin; Yürük, Nejla, Moyer-Packenham, Patricia)

Enacting functions from geometry to algebra (Steketee, Scott; Scher, Daniel)

Difference in self-reporting implementation of instructional strategies using a dynamic geometry approach (Webre, Brittany April)

The effect of dynamic geometry approach on geometry achievement and conjecture ability (White, Alexander Kevin; Smith, Shawnda; Cuevas, Gilbert)

\section{Saturday 30 July 2016}

Designing instruction towards mathematical literacy in geometry: a case study (Cheah, Ui-Hock)

Engaging students with non-routine geometry proof tasks (Cirillo, Michelle) Is the work of teaching geometry subject specific? (Herbst, Patricio G.) 


\section{Oral communications}

In addition to the selected papers there were another 20 oral communications and 13 poster presentations:

\section{Tuesday, 26 July 2016}

Combinatorial problems in school geometry (Smirnov, Vladimir Alekseevich)

Geometry opportunities for reasoning and proof in secondary school textbooks in trinidad and tobago (Hunte, Andrew Anthony)

Middle school students' (MIS)interpretations in length to volume relationships (Ayan, Rukiye)

Notes for the teaching of geometry in secondary school: a teacher training experience (Villella, José Agustín)

Artifact based geometric constructions (Siopi, Kalliopi)

Mathematics teachers' reflections using instructional design in the teaching of geometry (Jojo, Zingiswa Mybert)

Context integration effects on geometry learning of junior high school students (Chen, Ming-Jang)

Aspects of spatial thinking in problem solving: focusing on viewpoints in constructing internal representation (Arai, Mitsue)

Teachers' proving process in dynamic environment: the inscribed angle theorem (Nagar, Gili Gal)

Inquiry-based learning in geometry teaching (open-ended approach) (Ovsyannikova, Irina)

Center of gravity of various figures (Takayama, Takuma)

Are irrational numbers useful for what? going beyond perimeter, area and volume formulas (Mózer, Graziele Souza)

The use of writing as a metacognitive tool in geometry learning (Orozco Vaca, Luz Graciela)

The interplay between visualization and argumentation in the teaching of geometry (Papadaki, Chrysi)

\section{Friday, 29 July 2016}

Prospective teachers' personal and instructional definitions for quadrilaterals (Ulusoy, Fadime)

Irish pre-service teachers' subject matter knowledge of secondary level trigonometry (Walsh, Richard)

Geometry teaching knowledge: a comparison between pre-service and high school geometry teachers (Smith, Shawnda Rae)

Prospective teachers' knowledge about vectors and its applications to algebraic and graphical problems (Bulut, Neslihan)

Enhancing teaching and learning geometry through discovery approach: an example of Iran (Rabbi, Sima)

Is geometric literacy necessary? (Birni, Şeyda) 


\section{Poster Presentations}

- An analysis of actual conditions of justification to Korean new mathematics textbooks: focus on middle school geometry (Kim, Soocheol)

- Potentially significant teaching units involving 3d geometry and Thales' theorem (Manassés da Silva Batista, Raimundo Nonato Ferreira Tito Filho, Antonio Kennedy Lopes Dantas, Francismar Holanda Holanda)

- Black and light Tangram: learning from fun and interactive way (João Alves da Silva, Manassés da Silva Batista, Antonio Kennedy Lopes Dantas, Francismar Holanda)

- Educational value of the centroid of triangle (Tomohiro Ogihara, Tatsuya Mizogushi)

- Heuristic and inquiry based learning using the seifert graph (Yuki Osawa)

- Cooperative learning as a tool to teach a professional general course in university geometry (Wen-Haw Chen)

- Viewpoints and objects of the observation" in learning space figures (Shinya Ohta, Toshiji Matsubara)

- The concept of center of mass in teaching of geometry (ivko Dimitric)

- Variatio delectat: variation in mathematics (Chris Kooloos, Rainer Kaenders, Gert Heckman, Helma Oolbekkink)

- Doing geometry with 21st century tools and needs (Balvir Singh, Arthur Powell)

- Developing a learning and assessment framework for geometric reasoning to support teaching and learning in years 5-9 (Marj Horne, Rebecca Seah)

- Teaching analytic geometry emphasizing representations and translations (Sunghee Kim)

- School course of geometry: content selection and teaching material distribution (Samvel Haroutunian)

Open Access Except where otherwise noted, this chapter is licensed under a Creative Commons Attribution 4.0 International License. To view a copy of this license, visit http://creativecommons. org/licenses/by/4.0/.

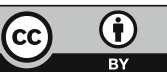

